\title{
IMMEDIATE IMPLANT PLACEMENT WITH IMMEDIATE PROVISIONALIZATION IN THE MAXILLARY ESTHETIC ZONE USING MIXTURE OF ALLOGRAFT AND XENOGRAFT VS XENOGRAFTS TO AUGMENT THE JUMPING GAP (A RANDOMIZED CLINICAL TRIAL)
}

\author{
Mohammed Nashmi Hammad*, Rami El-Bialy ${ }^{* *}$ and Mohammed Atef Abdel Rasoul***
}

\begin{abstract}
AIM: The aim of the study is to evaluate the efficacy of grafting material in the jumping gap and their effect on the marginal bone loss in upper esthetic zone by using mixture of allograft and xenograft versus xenograft.
\end{abstract}

Material and methods: A total of 20 extractions sockets, in 17 patients who had non-restorable maxillary teeth in the esthetic zone indicated for implant placement. They were selected from the outpatient clinic of the oral Maxillofacial surgery Department,Faculty of Dentistry, Cairo University. The study group where the peri- implant gap was filled with mixture of allograft and xenograft and the control group where the resultant gap following placement of implant was filled with xenograft. After implant placement, all patients received immediate and 6 months postoperative CBCT to assess the efficacy of grafting material in the jumping gap. The pink esthetic scores were measured at the time of implant placement and 6 months postoperatively.

Results: In the present study, twenty implants were placed in seventeen patients (10 females and 7 males) requiring replacement of maxillary anterior teeth. The implants used had diameters of 3.3, 3.7 and length of $14 \mathrm{~mm}$ in both groups. In the study group, 2 laterals and 6 centrals and 2 canine were extracted while in the control group 4 laterals and 5 centrals and 1 canine were extracted. the mean bone loss in study group $0.43 \pm 0.2 \mathrm{~mm}$ ranged from $0.18-0.9 \mathrm{~mm}$ compared to $0.34 \pm 0.1 \mathrm{~mm}$ in control group with range $0.13-0.5 \mathrm{p}=0.2193$. In addition, the soft tissue changes was evaluated immediately postoperative and 6 month later. The mean PES in the study group was $12.4 \pm 1.07$ and for the control group it was $12.7 \pm 0.82$. $\mathrm{P}=0.4906$.After 6 month the mean PES was $11.7 \pm 1.05$ for study group A and $12.1 \pm 0.73$ for control group $\mathrm{B}$. $\mathrm{P}=0.3357$

Conclusion: After comparing the results taken from both groups and comparing them to each other, we conclude that: -Immediate implant with immediate temporization is a viable technique for emergence profile preservation, which subsequently adds to better result regarding radiographic bony changes and pink esthetic score. -Xenograft as jumping gap filling material is successful for preservation labial cortical plate in immediate implant placement in the aesthetic zone.

\footnotetext{
* Faculty of Dentistry Cairo University

** Associate Professor of Oral and Maxillofacial Surgery, Faculty of Dentistry, Cairo University

*** Lecturer of Oral and Maxillofacial Surgery, Cairo University
} 


\section{INTRODUCTION}

Traditional Branemark protocol requires 12 months healing period after extraction of the tooth and healing period of 3-6 months after implant placement, this means that we need 1-2 years from beginning to the end of treatment which often leaves the patient with a missing tooth or teeth for extended a lot of time.

Immediate implant placement has a success rate from $94-100 \%{ }^{[1,2]}$. After tooth extraction there is a loss in the horizontal and vertical dimension by about 3-6 mm and 1-2 mm respectively and alveolar crest resorption of about 44\% especially through 6 months after extraction. The buccal plate is thinner than lingual plate by about 2-3 times and undergoes greater resorption horizontally and vertically [3]. Immediate implant placement has many advantages such as reduction of time of therapy and surgical procedures also preservation of bone and gingival tissues by maintaining support for the interdental papilla and psychological advantages, however it also has some disadvantages such as lack of control of final implant position, difficulty in obtaining primary stability, inadequate soft tissue coverage and the added cost of bone graft ${ }^{[4]}$.

After immediate implant placement there is usually distance between the implant and the socket walls which is called jumping gap which may heal spontaneously or need bone graft to bridge the space. If the gap is 1-2 mm it may heal spontaneously more than that this will need bone graft. There is no evidence that the graft impairs osseointegration $^{[5]}$. The use of bone graft in the gap will enhance osseointegration and post-operative healing. The gold standard grafting material is the autogenous bone graft, which is osteogenic, osteoconductive and Osseo inductive but it has some disadvantages such as inadequate bone volume, long surgical procedures, donor site morbidity, swelling, discomfort and pain.
Allograft bone is obtained from individuals of the same species, derived from human-cadaver bone that has been selected and tested to be free of HIV and transmitted diseases. Allograft bone which has osteoconductive properties. It binds to the bone by stimulation of osteoblast activity and enhance growth factors which improve bone healing and provide more strength?? and stability to the implant. It has certain advantages in periodontal tissue regeneration with minimal patient morbidity, better biocompatibility and lack of toxicity and inflammatory immune reaction. In addition, allografts offer several benefits when compared to autologous grafts, reductions in morbidity, discomfort, and surgical time ${ }^{[6]}$.

Achieving ideal esthetic results with dental implants is a challenge in the maxillary anterior region. Optimal implant position, enough volume of hard and soft tissues, and the presence of an interproximal papilla are essential. In last decades, the fixture left to Osseointegrate with bone and unloaded from 3 to 4 months. Newly, immediate loading of implants at the time of placement of implant or within few days have shortened the healing period and increase satisfy patient comfort and aesthetics. in comparing with late loading, immediate loading implant considered reliable and effective treatment to restore missing teeth and very attractive producers especially in area of aesthetics ${ }^{[7]}$.

Immediate implant placement in the maxillary esthetic zone is a more challenging due to the high esthetic requirements in this area, there is a large debates about grafting the gap that usually occur around the implant fixture due to size difference between the implant fixture and the extraction socket so, in this study we aim to evaluate the amount of marginal bone loss that occur after immediate implant placement with immediate provisionalization using mixture allograft and xenograft in the jumping gap and comparing it with xenograft in an attempt to decrease the post-operative bone resorption following tooth extraction. 


\section{MATERIALS AND METHODS}

A total of 20 extractions sockets, with 17 patients had non-restorable maxillary teeth in the esthetic zone indicated for implant placement. They were selected from the outpatient clinic of the oral and Maxillofacial surgery Department, Faculty of Dentistry, Cairo University. (Appendix 1)

Appendix 1: Patients Demographic Data

\begin{tabular}{|c|c|c|c|c|}
\hline Patient No & Sex & Age & $\begin{array}{l}\text { Number of } \\
\text { implants }\end{array}$ & Site number \\
\hline 1 & $\mathrm{~F}$ & 39 & 1 & 21 \\
\hline 2 & M & 35 & 1 & 12 \\
\hline 3 & M & 21 & 1 & 11 \\
\hline 4 & M & 38 & 1 & 13 \\
\hline 5 & $\mathrm{~F}$ & 29 & 1 & 22 \\
\hline 6 & $\mathrm{~F}$ & 34 & 2 & $\begin{array}{l}11 \\
21\end{array}$ \\
\hline 7 & $\mathrm{~F}$ & 37 & 1 & 11 \\
\hline 8 & $\mathrm{~F}$ & 22 & 1 & 21 \\
\hline 9 & $\mathrm{~F}$ & 26 & 1 & 23 \\
\hline 10 & M & 31 & 2 & $\begin{array}{l}11 \\
12\end{array}$ \\
\hline 11 & $\mathrm{~F}$ & 27 & 1 & 21 \\
\hline 12 & $\mathrm{~F}$ & 34 & 1 & 11 \\
\hline 13 & M & 36 & 1 & 23 \\
\hline 14 & $\mathrm{~F}$ & 29 & 1 & 11 \\
\hline 15 & M & 32 & 2 & $\begin{array}{l}12 \\
11\end{array}$ \\
\hline 16 & M & 23 & 1 & 21 \\
\hline 17 & $\mathrm{~F}$ & 39 & 1 & 12 \\
\hline
\end{tabular}

\section{Inclusion criteria:}

- Patients with non-restorable maxillary teeth in the aesthetic zone indicated for implant placement. Presence sufficient bone structure at least $5 \mathrm{~mm}$ beyond the apex of the extraction socket.
- $\quad$ Both sexes.

- No intraoral soft or hard tissue pathology.

- No systemic condition that contraindicate implant placement.

- Good oral hygiene. Exclusion criteria:

- Presence of fenestrations or dehiscence of the residual bony Walls after extraction.

- Patients with systemic diseases that would interfere with the normal healing such as uncontrolled diabetes mellitus, history of radiation therapy to the head and neck, and Previous bone augmentation procedure at implant.

- Teeth with periapical lesion larger than $2 \mathrm{~mm}$.

The present study was approved by the ethics committee of the Faculty of Dentistry, Cairo University.

The seventeen patients were randomly divided into the study and control groups using computer assistant generated number software.

- The study group: included 10 extraction sockets in 9 patients which received immediate post extraction implant placement with mixture of allograft and xenograft to augment the gap between the residual labial bone and implant surface with immediate temporization.

- The control group: included 10 extraction sockets in 8 patients which received immediate post extraction implant placement with xenograft to augment the gap between the residual labial bone and implant surface with immediate temporization.

- Preoperative Assessment

A thorough preoperative assessment for all enrolled candidates was carried out including history taking, clinical and radiographic examination.

- Patient Interview:

o Each patient was interviewed in order to obtain a comprehensive history, including full medical and dental history. 
- Clinical Examination:

o Patients were inspected for adequate Inter- arch and mesiodistal space.

o The ridge was palpated to check the contour for any abnormalities that may contraindicate implant placement.

Thorough periodontal examination was carried out checking the mucosa color, contour and consistency. Probing depth readings was recorded and checked for any Probing depth on probing.

\section{Radiographic Examination:}

o A Preoperative digital panoramic radiograph (orthopantogram) with 1:1 magnification was taken to evaluate the crestal bony level around teeth, presence of any impacted teeth or pathological lesions in area of interest.

o Cone beam computer tomography CBCT scan (Planmeca Promax 3D, Planmeca, Finland) was ordered for enrolled candidates to assess the labial bone thickness, bucco-palatal bone width, height and select the proper implant size to be used. Panoramic of CBCT assess the mesiodistal dimension of teeth and its relation to neighboring teeth, and assessment the relationship of apex root to nasal floor.

\section{Surgical procedures for both groups :}

-A Cone Beam Computed Tomography CBCT scan was ordered for the enrolled candidates to assess the labial bone thickness, available bone height and select the proper implant size to be used. (Figure 1)

- The extraction started using a periotome to sever the periodontal ligaments around the root. Then forceps were used to deliver the tooth out of its socket using gentle extraction movements to preserve buccal plate of bone.

- Curettage of the socket and irrigated with saline to remove any debris.

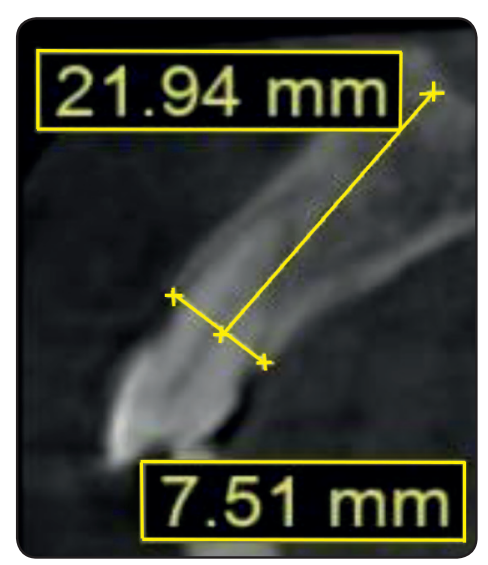

Fig. (1) Cross section showing the calculation of the vertical and horizontal dimensions of the ridge.

- The integrity of the extraction socket was checked using a periodontal probe. If any dehiscence or fenestration defects were found, the case was excluded from the study.

- Drilling were started in a sequence manner and implant (S-clean implant, Dentis Company, Kore) were placed bodily palatal in the undersized osteotomy to increase the primary stability followed by measurement of the jumping gap distance.

- After that the torque wrench was attached to complete the seating of the implant into its final position, with implant placement sub-crestal at least $3 \mathrm{~mm}$ below cemento- enamel junction of adjacent tooth.

- The primary stability of each implant was measured using torque wrench ratchet, if the primary stability found to be less than $35 \mathrm{~N} / \mathrm{cm}$ the case was excluded from the study, Then the cover screw was placed.

- For study group: using mixture 50\% allograft (maxgraft, botiss, Austria) and 50\% xenograft (Geistlich, biooss, bovine, Switzerland). for augmentation of the gap between the implant and the labial plate of bone. 
- For control group: using xenograft for augmentation of the gap between the implant and the labial plate of bone.

- A provisional crown was then constructed chairside on stock straight titanium abutment with an emergence profile to support the coronal tissues. All provisional crowns were relieved out of occlusion with an approximate clearance of $1 \mathrm{~mm}$, and the patients were instructed to avoid functional overloads.

\section{Post-operative care and follow up.}

- Postoperative medications included oral antibiotic, a dose of $1 \mathrm{~g}$ twice daily for 5 days (Amoxicillin/Clavulanic acid [Augmentin $1 \mathrm{~g}$ tab., Pfizer, United States of America]) and an oral analgesic, a dose of $400 \mathrm{mg}$ three times daily for 5 days (Ibuprofen [Brufen 400MG 30tab. Abbott/Cairo, Egypt]).

- The patients followed strict oral hygiene measures and regular rinsing of Chlorohexidine $0.2 \%$ (Orovex mouthwash, Macro group, Egypt) mouthwash for 2 weeks. The patients were followed up every other day for the first week, then weekly for the first month and 6 months postoperatively.

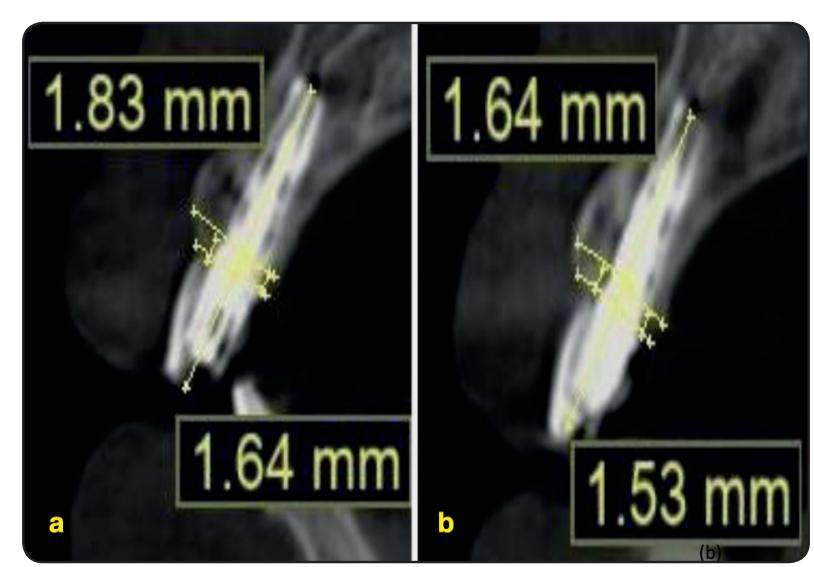

Fig. (2) Showing horizontal $(\mathrm{H})$ and vertical (V) bone level in study groups immediately(a) postoperative and (b) 6 month later.

\section{Post-operative Assessment:}

\section{1: Radiographic evaluation:}

In all patients, a cone beam computed tomography (CBCT) was made immediately postoperative and 6 month later to assess the horizontal and vertical dimensional changes to of the labial plate of bone.

Cross section was used to measure bone dimensional changes as follow:Calculation was made on CBCT cross-section by a line drawn vertically passing through implant center. A horizontal line was drawn passing through the implant platform. Another horizontal line passing from the buccal bone margin perpendicular to the line bisecting the implant center, then the distance between the implant platform and the horizontal line was measured representing the buccal marginal bone loss if present. A line was drawn from the lingual bone margin perpendicular to the implant platform bisecting line. The distance between the implant platform and the lingual line was measured representing the lingual marginal bone loss. The average of 2 reading was taken represent the marginal bone loss. (figure 2-3)

\section{2: Pink esthetic evaluation:}

The pink esthetic was evaluated immediately postoperative and 6 month later.

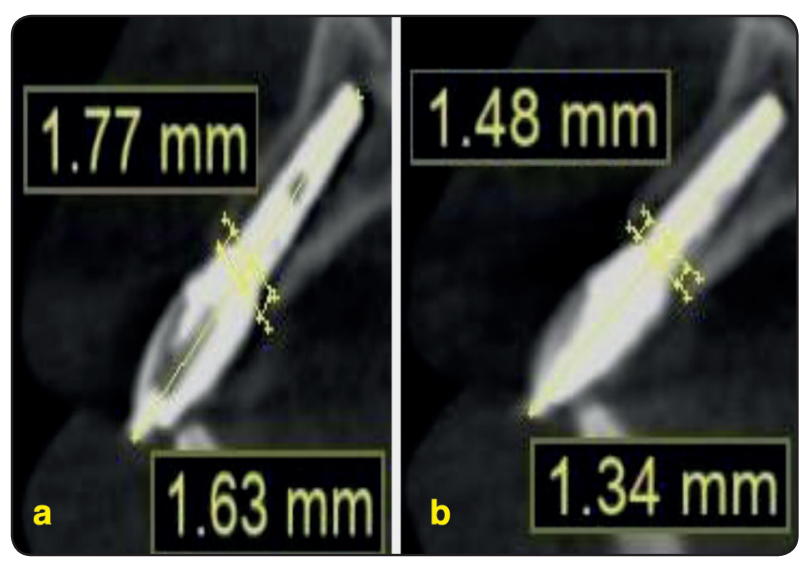

Fig. (3) Showing horizontal $(\mathrm{H})$ and vertical (V) bone level in control groups immediately(c) postoperative and (d) 6 month later of patient number. 


\section{Pink esthetic evaluation criteria:}

The Pink Esthetic Score (PES) is based on seven variables: mesial papilla, distal papilla, soft-tissue level, soft tissue contour, alveolar process deficiency, soft-tissue color and texture Each variable was assessed with a 2-1-0 score, with 2 being the best and 0 being the poorest score.

The mesial and distal papillae were evaluated for completeness, incompleteness or absence. All other variables were assessed by comparison with a reference tooth, i.e. the corresponding tooth (anterior region) or a neighboring tooth (premolar region) The highest possible score reflecting a perfect match of the peri-implant soft tissue with that of the reference tooth was 14. (Furhauser et al. 2005) ${ }^{[8]}$.

\section{Statistical methods}

Data management and statistical analysis were performed using the Statistical Package for Social Sciences (SPSS) version. 24. Numerical data were summarized using means, standard deviations, and range. Data were explored for normality using Kolmogrov-Smirnov test and Shapiro-Wilk test. Comparisons between the 2 groups were done using the independent $\mathrm{t}$-test. Comparison over time was done by paired $t$ test in each group. Categorical data were summarized as number and percentage. Comparisons between 2 groups regarding categorical data were done using chi square test. All p-values are two-sided. P-values $\leq 0.05$ were considered significant.

\section{RESULTS}

In the present study, twenty implants were placed in seventeen patients (10 females and 7 males) requiring replacement of maxillary anterior teeth. The implants used had diameters of 3.3, 3.7 and length of $14 \mathrm{~mm}$ in both groups.

In the study group, 2 laterals and 6 centrals and 2 canine were extracted while in the control group 4 laterals and 5 centrals and 1 canine were extracted.

\section{Marginal bone Loss}

As shown in table (3) the mean bone loss in study group A $0.43 \pm 0.2 \mathrm{~mm}$ ranged from $0.18-0.9$ $\mathrm{mm}$ compared to $0.34 \pm 0.1 \mathrm{~mm}$ in control group $B$ with range 0.13-0.5. This was statistically nonsignificant $\mathrm{p}=0.2193$. (figure 4 )

TABLE (1) Mean, SD, median, range and Mann Whitney test of bone loss percentage in the studied groups

\begin{tabular}{|c|c|c|c|c|}
\hline \multicolumn{5}{|c|}{ Study group A Control group B P value } \\
\hline \multirow{2}{*}{$\begin{array}{c}\text { Crestal } \\
\text { bone loss }\end{array}$} & Mean \pm SD & $0.43 \pm 0.2$ & $0.34 \pm 0.1$ & 0.2193 \\
\cline { 2 - 5 } & Range & $0.18-0.9$ & $0.13-0.5$ & \\
\hline
\end{tabular}

SD: standard deviation, $\mathrm{P} \leq 0.05$ is considered statistically significant

In group A: The mean bone height changed from $1.68 \pm 0.32 \mathrm{~mm}$ immediately to $1.28 \pm 0.38 \mathrm{~mm}$ at 6 months postoperative, this was statistically significant $\mathrm{P}=0.02$

In group B: The mean bone height changed from $1.88 \pm 0.21 \mathrm{~mm}$ immediately to $1.54 \pm 0.18 \mathrm{~mm}$ at 6 months postoperative, this was statistically significant $\mathrm{P}=0.001$
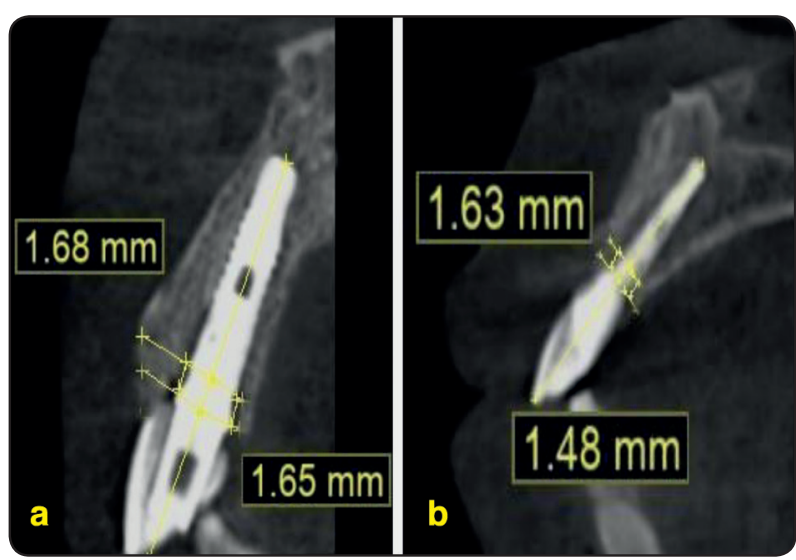

Fig. (4) Showing the bone level after 6 months in study group (a) patient number 6 and control group (b). 


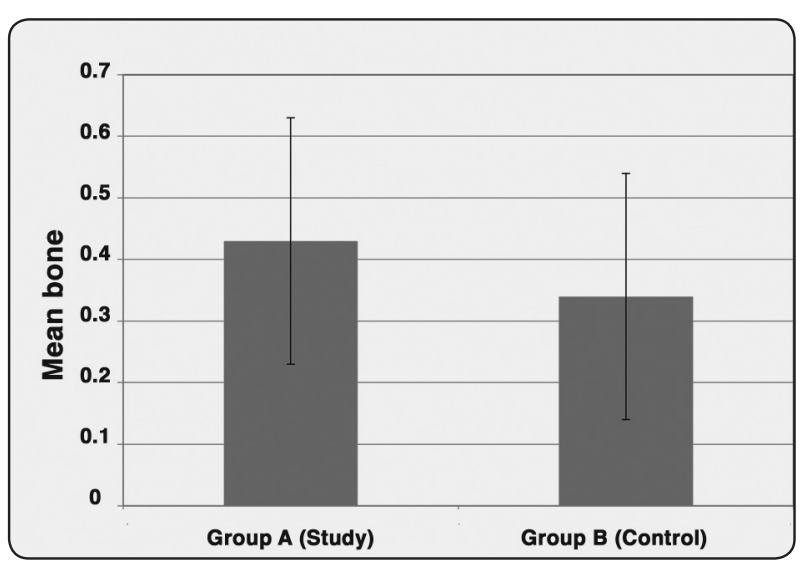

Fig. (5) Bar chart representing mean and SD of PES immediately between the studied 2 groups

\section{Pink esthetic score}

The results of PES postoperative immediately and after 6 months represented in table 2 and figure 5 . Immediately; the mean PES in the study group was $12.4 \pm 1.07$ and for the control group it was $12.7 \pm 0.82$. This was statistically nonsignificant $\mathrm{P}=0.4906$. After 6 month the mean PES was $11.7 \pm 1.05$ for study group A and $12.1 \pm 0.73$ for control group $\mathrm{B}$. This was statistically nonsignificant $\mathrm{P}=0.3357$

TABLE (2) Mean, SD and range of PES in the studied groups

\begin{tabular}{|c|c|c|c|c|}
\hline \multicolumn{2}{|c|}{ PES } & $\begin{array}{c}\text { Study } \\
\text { group A }\end{array}$ & $\begin{array}{c}\text { Control } \\
\text { group B }\end{array}$ & Pvalue \\
\hline Immediately & Me & $12.4 \pm 1.07$ & $12.7 \pm 0.82$ & 0.4906 \\
\hline & $\begin{array}{c}\text { Median } \\
\text { (Range) }\end{array}$ & $12(11-14)$ & $12(12-14)$ & \\
\hline 6 months & $\begin{array}{c}\text { Mean } \pm \\
\text { SD }\end{array}$ & $11.7 \pm 1.05$ & $12.1 \pm 0.73$ & 0.3357 \\
\hline & $\begin{array}{c}\text { Median } \\
\text { (Range) }\end{array}$ & $11(10-13)$ & $12(11-13)$ & \\
\hline
\end{tabular}

$P \leq 0.05$ is considered statistically significant

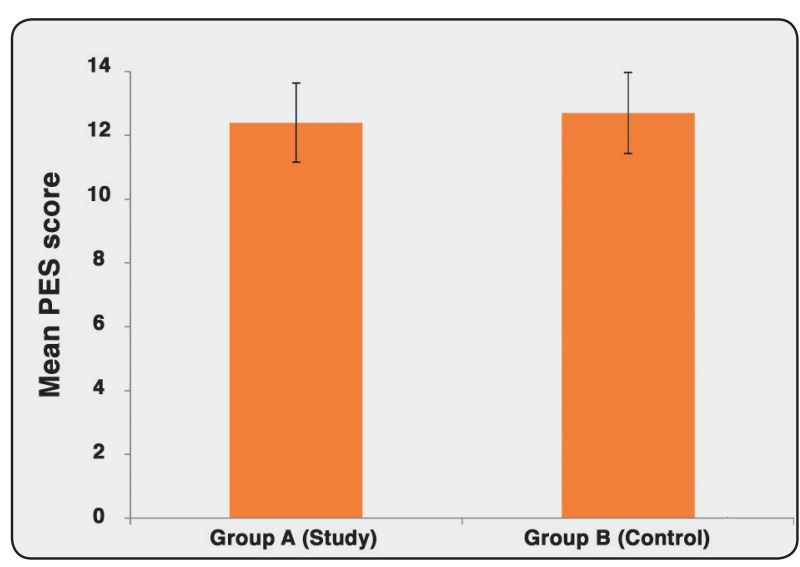

Fig. (5) Bar chart representing mean and SD of PES immediately between the studied 2 groups

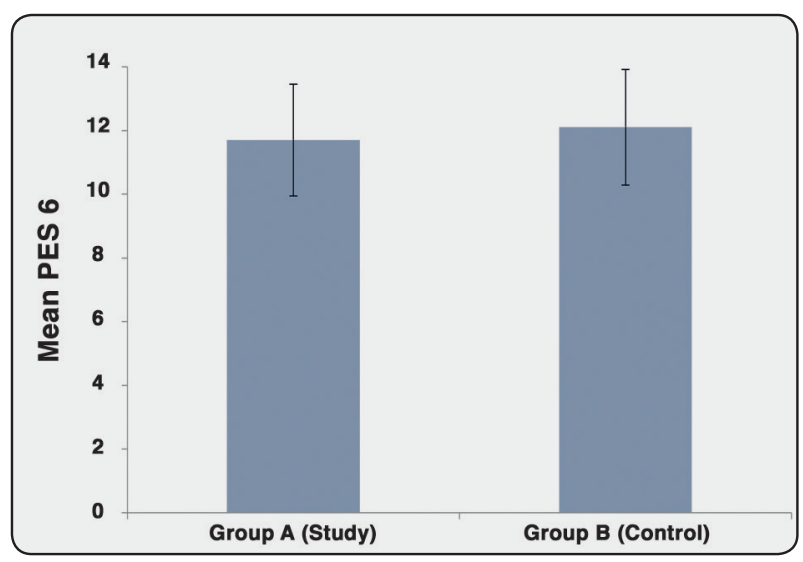

Fig. (7) Bar chart representing mean and SD of PES after 6 months between the studied 2 groups.

\section{DISCUSSIN}

Traditional implant placement protocols suggested waiting up to 6 months following tooth extraction before implant placement. The clinical consequences of this approach include alveolar bone loss and soft tissue collapse due to postextraction resorption which leading to difficulties in implant placement and compromise the æsthetics appearance. Based on clinical reports, immediately placed implants seemed to have success comparable with those inserted in a conventional way. Lazzara et al (1989) ${ }^{[9]}$ concluded the immediate implant placement could allow bone preservation of 
extraction sites. Schwartz et al (2000) ${ }^{[10]}$ evaluated 5 years clinical study of 56 immediate implant into fresh extraction socket of 43 patients which conducted the survival rate was $89 \%$ during the fiveyear follow-up. However, Sometimes the socket is larger than the diameter of the implant being placed which will create a gap between implant surface and labial bone which is called jumping gap [11]. The management of this gap has become a novel challenge. Accordingly, this study presented to evaluate the management of gap around immediate implant placement with immediate temporization by using mixture of allograft and xenograft versus xenograft to evolution their effect of marginal bone loss in anterior maxilla.

A lot of studies suggested that the small gaps between implants and extraction sockets will fill with bone with or without bone grafting procedures. Boticelli et al (2004) ${ }^{[12]}$ conducted study showed jumping gap following implant placement may predictably heal with new bone formation. Others showed that bone augmentation procedures may be needed. Kahnberg et al (2009) ${ }^{[13]}$ claimed that patients whose implanted sockets were filled with bone graft material showed better results than patients who did not receive bone graft. Furthermore, Araújo et al. (2011) ${ }^{[14]}$ suggested to fill this gap with a biomaterial for many reasons including modification of hard tissue healing process, prevention of soft tissue recession, and improvement of the marginal bone-to-implant contact. In this presented study compared 20 extraction sockets receiving immediate implant placement with bone grafts, 10 extraction sockets(study group) received mixture of allografts and xenografts, where the remaing 10 extraction sockets (control group) received xenograft by using two- piece implant which placing immediately into fresh extraction sockets of 17 patients.

The genetically non identical bone graft (allograft) has many advantages which are availability in large quantities and the composition and structure which is similar to the natural bone which considered to be osteoinductive and osteoinduc- tive $^{[85]}$. Koutouzis et al (2010) ${ }^{[15]}$ showed the effect of allograft on marginal bone loss Which concluded the implants placed in post-extraction sockets augmented with allograft exhibited minimal marginal bone loss. Furthermore, the use of non-human species has osteoconductive properties (xenograft) serve to maintain tissue volume after bone regeneration due it a slow substitution rate. The interconnecting pores of the trabecular structure of bovine bone facilitate growth of bone ${ }^{[16]}$. Schropp et al (2003) ${ }^{[17]}$ recommended the placement of xenograft to compensate the hard tissue lost after a tooth extraction. However, some clinicians prefer to mix different bone graft materials in order to take advantage of these graft.

Serrano et al (2018) ${ }^{[18]}$ evaluation of a combination of allograft and xenograft for ridge preservation. The socket was treated by using a combination of allograft and xenograft. After 4 months of healing the clinical measurement were taken and showed bone dimensional changes were small and demonstrated the Favorable clinical results were observed after the use of the combined bone graft. Accordingly, this present evaluated the effect of grafting material (mixture allograft and xenograft) versus (xenograft) in marginal bone loss. the result showed the mean bone loss in study group $0.43 \pm 0.2 \mathrm{~mm}$ ranged from $0.18-0.9 \mathrm{~mm}$ compared to $0.34 \pm 0.1 \mathrm{~mm}$ in control group with range 0.13 0.5 . This was statistically non-significant difference.

From previous result it at appear the control group which received xenograft showed minimal bone loss compared to study group which received mixture allograft with xenograft. These results do not agree with Serrano et al (2018) who showed that after the combined use of allograft and xenograft the minimaldimensional changes occurs. However, it agrees with kyun et al (2008) ${ }^{[19]}$ which concluded that mixed grafting with demineralized bone matrix for grafting has no significant short-term regarding bone healing and stability of implants compared with bovine bone alone. 
In another hand, Furhauser et al (2005) ${ }^{[20]}$ suggested index termed the pink esthetic score (PES) which basically on the soft tissue aspects of an anterior implant restoration. In this presented study we evaluated the pink esthetic score which showed there was small difference between groups: the mean PES for study group was $(11.7 \pm 1.05)$ and was for control group $(12.1 \pm 0.73)$. This was statistically non- significant. From our result it would appear there are no difference in soft tissue parameters regrading to different bone grafts material used, but temporization have a great role in saving and shaping soft tissue following immediate implant placement. Chan et al (2019) ${ }^{[21]}$ said placement implant with immediate. Provisionalization achieved stable vertical soft tissue.

In addition, Cosyn et al (2016) ${ }^{[22]}$ evaluated study on soft tissue preservation and pink esthetic on 22 implants were placed after tooth extraction. The result showed is closely matching of result of this presented study which showed the mean PES score were 12. And concluded that pink esthetic can be preserved by immediate implant treatment and provisional restoration. However, in this present study using different provisional restoration such as extraction tooth and PMMA. The extraction tooth has advantages which easy manipulation and have same morphology and color. Also, it provides good emergence profile. In addition, this is particularly benefiting for the thin periodontium, where there is greater chance for bone and tissue recession. Wendy et al (2015). ${ }^{[23]}$ It is crucial for sub gingival contour supported the peri-implant tissue. However, placing the implant in correct three-dimensional safely zone help to achieve optimal aesthetic and biologic integration. These are buccolingual, mesiodistal and apicocoronally positions relative to implant platform as well as the angulation of implant. The implant head should be a minimum of $3 \mathrm{~mm}$ apical to an imaginary line connecting the cemento-enamel junctions of the adjacent teeth and apical to the interproximal and crestal bone. Su et al (2010) ${ }^{[24]}$ showed the depth of the implant is critical since the restoration must have sufficient room to create an ideal transition from the implant platform to the prospective gingival margin. Also, buccal-lingual implant position determines the long-term soft-tissue aesthetics around the implant restoration placing implant in palatal approach help to maintain soft and hard tissue. Lee et al. $(2014)^{[25]}$ conducted study showed it important to placing implant bodily palatal to avoid surgical trauma and impingement of the internal aspect of the labial plate, which have a great role in limiting resorption of labial plate. The osteotomy in this present study was performed by following previous guidelines to maintain the peri-implant tissue volume which improving clinical and esthetic outcomes to get easy fabrication of the prosthesis, esthetically ideal results, and stable occlusal dispersion. ${ }^{[26]}$ we take attention about securing the stability of the implant. It is advisable to achieve primary implant stability placing the implant from 3-5 mm into the bone ${ }^{[27]}$. Tapered implant can be placed into the extraction socket with minimal or no osteotomy preparation depending on engagement of threads to the bone lateral to the socket walls. The theory behind used tapered dental implant connections is to exert a degree of compression on cortical bone in a relatively poor bone implant site to increase primary stability. Moreover, Chong et al. (2009) ${ }^{[28]}$ showed the tapered implants distribute forces into the surrounding bone, which creating a more uniform compaction of bone in adjacent osteotomy walls. In this study we did not find statically significant differences in bone height changes between the two groups. Although the differences between approaches were small. There are no clear evidence to suggest that immediate implant placement in association with a regenerative procedures may be useful in prevent alveolar bone resorption. However, the temporization is an effective method to modeling soft tissue around dental implants. In addition, placing of provisionalization restorations at the time of surgery have a great effect on the emergence profile which producing good result outcome. 


\section{CONCLUSION}

This study was performed to evaluate marginal bone loss using mixture allograft and xenograft versus xenograft in immediate implant placement with temporization in esthetic area. Twenty implants were conducted in twenty fresh extraction sockets in 17 patients with one or more hopeless teeth indicated for extraction in the region of maxillary anterior teeth. All patients were systemically free and with reasonable oral hygiene.

Extraction sockets were randomly distributed into two groups. The first study group received immediate post-extraction implants with mixture allograft with xenograft to fill the peri-implant bony defect (jumping gap) While control group received immediate post-extraction implants with bovine xenograft to fill the peri-implant bony defect.

Preoperative measures were performed including clinical and radiographic assessment to ensure proper case selection. A traumatic protocol was followed to deliver the tooth outside the socket. The implants were placed simultaneously in fresh extraction sockets after proper irrigation. The patients of study group received mixture allograft with xenograft to fill the marginal gap while control group received bovine xenograft. The bovine xenograft and mixture allograft with xenograft were mixed with saline and were introduced inside the gap using a graft carrier and condensers. The graft was packed loosely to allow for pooling of blood between the graft particles.

A provisional crown were used with an emergency profile to support the coronal tissues. All provisional crowns were made out of occlusion and patients were instructed not to occlude on them and to use for esthetic appearance only.

A cone beam CT was taken immediately postoperative and 6 months postoperatively to measure the amount of marginal bone loss in each group and then the percentage of bone loss in each group was compared to the other group.
The mean bone loss in study group $0.43 \pm 0.2 \mathrm{~mm}$ compared to $0.34 \pm 0.1 \mathrm{~mm}$ in control group. This was statistically non-significant.

Also, the pink esthetic was evaluated immediately postoperative and 6 month later to assessment the soft tissue changes after immediate implant placement with different bony grafts material. Immediately; the mean PES in the study group was $12.4 \pm 1.07$ and for the control group it was $12.7 \pm 0.82$. This was statistically nonsignificant $\mathrm{P}=0.4906$

After 6 month the mean PES was $11.7 \pm 1.05$ for study group A and 12.1 \pm 0.73 for control group B . This was statistically nonsignificant $\mathrm{P}=0.3357$

Results demonstrated a small amount of marginal bone loss in both groups. There was more marginal bone loss in study group (with mixture allograft with xenograft) than control group (xenograft) but it was not statistically significant.

\section{REFERENCES}

1. Lazzara RJ. Immediate implant placement into extraction sites surgical and restorative advantages. Int J Periodontics Restorative Dent .1989.

2. Ashman A. An. Immediate tooth root replacement an implant cylinder and synthetic bone combination. J Oral Implantol .1990.

3. Adell R, Lekholm U, Rockler. 15-year study of osseointegrated implants in the treatment of the edentulous jaw. Int J Oral Surg .1981.

4. Schwartz-Arad D, Chaushu G. The ways and wherefores of immediate placement of implants into fresh extraction sites: a literature review. J Periodontol .1997.

5. Wilson TG Jr, Schenk R, Buser D. Implants placed in immediate extraction sites: a report of histologic and histometric analyses of human biopsies. Int J Oral Maxillofacial Implants. 1998.

6. D.H. Perrott, R. A. Smith, and L. B. Kaban, "The use of fresh frozen allogeneic bone for maxillary and mandibular reconstruction," International Journal of Oral and Maxillofacial Surgery. 2017.

7. Tettamanti L, Andrisani C, Bassi A, Vinci R, SilvestreRangil J, \& Tagliabue A. Immediate loading implants: review of the critical aspects. 2017. 
8. Fürhauser, R., Florescu, D., Benesch, T., Haas, R., Mailath, G. and Watzek, G. Evaluation of soft tissue around singletooth implant crowns: the pink esthetic score. Clinical Oral Implants Research .2005.

9. Lazzara RJ. Immediate implant placement into extraction sites: surgical and restorative advantages. Int J Periodontics Restorative Dent. 1989.

10. Schwartz-Arad, D., Grossman, Y. and Chaushu, G.The Clinical Effectiveness of Implants Placed Immediately Into Fresh Extraction Sites of Molar Teeth. Journal of Periodontology. 2000.

11. Meloni SM, Jovanovic SA, Pisano M, Tallarico M. Platform switching versus regular platform implants: 3-year post-loading results from a randomized controlled trial. Eur J Oral Implanted. 2016.

12. Botticelli D, Berglundh T, Lindhe J. Hard-tissue alterations following immediate implant placement in extraction sites. J Clin Periodontol. 2004.

13. Kahnberg, K.E. Immediate implant placement in fresh extraction sockets: a clinical report. International journal of oral and maxillofacial implant 2009.

14. Araujo MG, Linder E. Wennstron J. Lindhe J. The influence of Bio-Oss collagen on healing of an extraction socket: an experimental study in the dog. The Int J of Per Res Dent. 2008.

15. Koutouzis, T., \& Lundgren, T. Crestal Bone-Level Changes Around Implants Placed in Post-Extraction Sockets Augmented with Demineralized Freeze-Dried Bone Allograft: A Retrospective Radiographic Study. Journal of periodontology. 2010.

16. Urist MR, Silverman BF, Buring K. The bone induction principle. Clin Orthop Relat Res. 1967.

17. Schropp L, Wenzel A, Kostopoulos L. Bone healing and soft tissue contour changes following single-tooth extraction :
A clinical and radiographic 12-month prospective study. Int J Periodontics Restorative Dent. 2003.

18. Serrano CA1, Castellanos P2, Botticelli D3. Use of Combination of Allografts and Xenografts for Alveolar Ridge Preservation Procedures: A Clinical and Histological Case Series. Implant Dent. 2018.

19. Chen ST, Darby IB, Reynolds EC, Clement JG. Immediate implant placement postextraction without flap elevation. J Periodontol. 2009.

20. Cosyn J., Hooghe N., De Bruyn H. A systematic review on the frequency of advanced recession following single immediate implant treatment. Journal of Clinical Periodontology. 2012

21. Wendy C.W. Wang. Utilization of extracted teeth as provisional restorations following immediate implant placement. 2015

22. Su, Huan \& Gonzalez-Martin, Oscar \& Weisgold, Arnold \& Lee, Ernesto. Considerations of Implant Abutment and Crown Contour: Critical Contour and Subcritical Contour. The International journal of periodontics \& restorative dentistry. 2010.

23. Lee EA, Gonzalez-Martin O, Fiorellini J. Lingualized flapless implant placement into fresh extraction sockets preserves buccal alveolar bone: a cone beam computed tomography study. 2014.

24. Gursharan Kaur, Dr. Rubina Tabassum, Dr. Gaurang Mistry, Dr. Omkar Shetty, Immediate Implant Placement, IOSR Journal of Dental and Medical Sciences. 2017.

25. Gary Greenstein, and John Cavallaro. Immediate Dental Implant Placement: Technique, Part 1, AGD endorsement. June 1, 2012 to May 31, 2015.

26. Chong L, Khocht A, Suzuki JB. Effect of implant design on initial stability of tapered implants. J Oral Implantol. 2009 . 